\title{
Mastery Motivation and Secure Attachment among Preschool Children in the Light of Depending on Domestic Workers in the Saudi Society
}

\author{
Azza Khalil Abdulfattah ${ }^{1,2} \&$ Asma Saeid Badawood ${ }^{1}$ \\ ${ }^{1}$ Educational Policies and Kindergarten Education College, King Saud University, Saudi Arabia \\ ${ }^{2}$ Child Education Department, EinShams University, Egypt \\ Correspondence: Asma Saeid Badawood, Educational Policies and Kindergarten Education College, King Saud \\ University, Saudi Arabia. E-mail: profasmabadawood@gmail.com
}

\author{
Received: December 9, $2016 \quad$ Accepted: January 29, $2017 \quad$ Online Published: April 29, 2017 \\ doi:10.5539/ies.v10n5p204 \\ URL: https://doi.org/10.5539/ies.v10n5p204
}

This research project was supported by a grant from the Research Center for the Humanities, Deanship of Scientific Research, King Saud University, 2016.

\begin{abstract}
The current study aims to verify the impact of children's secure attachment to their mothers on their mastery motivation in the light of the dependence on domestic workers' phenomenon in the Saudi society. To achieve the goals of the study, a random sample of Saudi children was selected from Riyadh city in Saudi Arabia, whose favorable economic circumstances contributed in the dependence of their families on domestic workers. The sample is consisted of two pre-school children groups who were under six years old; the first group is consisted of (74) child whose families depend on domestic workers, while the second group is consisted of (109) child from families who do not depend on domestic workers to care for their children. The outcomes were collected after applying DMQ 17 questionnaire for assessing mastery motivation for children below the age of 6 for George Morgan. The results showed that early attachment's relationship with mothers has a prominent impact on the mastery motivation development. Moreover, the outcomes showed no significant effects of domestic workers who are in charge of housekeeping, and care services on all mastery motivation dimensions.
\end{abstract}

Keywords: secure Attachment, mastery motivation, domestic workers, Saudi children

\section{Introduction}

Cognitive Psychology consider motivation as an executive functioning, which moves human beings towards action, and tasks that in turn will contribute in achieving their objectives (Dunning, 2004). Theoretically the higher levels of mastery motivation which reflected in extensive exploratory behavior in early years of life, will work to increase interaction between the child and his environment, which will result in better developmental outcomes for toddlers (Wang et al., 2013). Moreover, it has been agreed that secure attachment in infants, could be a predictor of a variety of later outcomes in childhood, such as good cognitive and social development. Also, it may have a positive impact on ego-strength, psychological resiliency, independence, low psychological risks, and behavioral problems (Pierrehumbert et al., 2000).

Attachment relation describes the emotional intimate relation between the baby and few caregivers who are responsible to guarantee his comfort, support, feeding, and protection. Accordingly, the child learns from repeatable experiences, that those caregivers are available and reliable. The variance between attachment types, especially if it was formulated or not, has important sequences on the infants' development. Children who have abused attachment experiences; i.e. irregular attachment relationships or the absence of attachment relationships as the case in reactive attachment disorder, may face great danger as to their current and future mental health, (Breidenstine et al., 2011). Attachment concept is used to describe the attachment relationship developed by the child towards caregivers. This relationship could be witnessed during the second half of his first year of his/her life, and continue to develop steadily through the first four years of his/her life. This relationship is reflected on children's behavior when they are ill, injured, tired, obsessed, or hungry, (Pearce, 2009) or once meeting a strange person; as in "the strange situation test" which is designed to verify children's types of attachment through stressful situation represented by meeting unfamiliar person. 
(Bowlby et al., 2011) defined attachment as an emotional relationship between the infant with his caregiver/s which is expressed through attachment behavior represented by crying, clinging, and running after his caregiver to establishing and maintaining close attendance, especially in stressful situations. Bowlby believed that attachment; which he considers as an "Instinctive behavior" is not a stereotyped behavior but highly sensitive performance of specific individual in a specific environment. Nevertheless, the Anthropological, and cultural psychological view shed doubts on the globalization of this emotional relation in all cultural environments (Keller, 2014). It is supposed that the socialization of children differs from one community to another, also in many traditional communities; emotions' expression is a subject to community restrictions and traditions. In some communities' emotions' expression, may not be allowed nor supported by parents, especially during an interaction between children and adults. In spite of considering facing a stranger as a crucial situation, that provoke the attachment behavior of children, in a study conducted on a sample of children of Cameron (Keller et al., 2011), the results showed that most of the children (most of them were farmer's children) did not show any emotional expressions while meeting with a stranger. Moreover they found that levels of cortisol in their bodies were low, during the interaction with the strange person. In another study (Gottilieb, 2004) conducted on Beng people in Cote d'Ivoire, it was found that children are trained, since early ages, to welcoming strangers. These results and others refer to the fact that attachment relationships are organized in different methods through different cultural environments (Otto \& Keller, 2014)

According to that, the current study focuses on the potential effects of the early attachment relationships with mothers on mastery motivation of a sample of early childhood children from the Saudi society in the light of the noticeable reliance of Saudi families on domestic workers, in house managing and in caring for children in different degrees. Which raises inquiries about the powerful attachment relationships with mothers in that society: the possible effects on attachment relationships in one side, and the effects of increased reliance on domestic workers on children mastery motivation on the other side?

One of the early developmental systems displayed in the first two years of childhood is the "Ego-system". This system reflects the activities that children chose to participate in, how they response towards failures and challenges in their selected activities, adopted behavior standards, self-assessment according to such standards, the resulted emotions they experience, and their general feelings of self-value. Also, the children try to recognize the external standards of their behavior and the accompanying self-evaluation which is reflected via displaying pride and shame originating from achieving such standards. Another important characterization of child's early self-representation, is mastery motivation (i.e. internal motive leading young children towards exploring their environment and mastering it), which is expressed through interest and persistence in challenging tasks (Kelley et al., 2000)

Until recently, motivation was considered as an individual phenomenon. The theorists who work on motivation adopted a vision on motivation structure by using individualistic terms. They focused on individualized nature of motivation in spite of their recognition of social factors, social context, and their impact on such individual process, since long time. Recently they started to scrutiny such concepts, which lead to recognizing the effects of social and cultural environment on development (Walker et al., 2010). Mastery motivation is considered as a multi-faceted Psychological strength that provokes children's attempts to master tasks of moderate challenge. Mastery motivation focuses more on persistence. Concentration on tasks of moderate challenge is considered a reflection of concepts of "Match" of zone of proximal development, which could offer the highest levels of motivation (Wang et al., 2013). The desire to solve problems that carry cognitive challenges to individuals for the sake of pleasure generated from the discovery of solution, this pleasure was regarded as a determinant factor that works in pushing children to take more time in solving problems, this kind of determinants is more important for the child and makes him spend more time and involvement in solving problems, compared to his desire of acceptance and appreciation. Although acceptance from adults has significant impact on the child behavior, but it is replaced during development, by motivation system, whereas mastery and cognitive efficiency are more prominent and also the pleasure gained from finding the solution has more impact (Harter,1957). Personal interest is the main factor for promoting intrinsic motivation as it directs individuals' attention towards the mission, and, strengthens new environments' discovery attempts. Deci \& Richard (1985) concluded that interest and pleasure are central feelings that accompany intrinsic motivation (Moneta, 2004).

Mastery motivation is a type of intrinsic motivation which means an independent persistence of the child to complete moderate challenging task. This motivation type received central scope by researchers who tackled childhood issue in its normal developmental and in the course of developmental disability. This mastery motivation is also considered as a part of self-regulatory attention system, through which it is possible to predict the cognitive efficiency of young children (Young \& Hauser-Cram, 2006). However; the activities which fulfill 
the control need and efficiency are enhancing intrinsic motivation. Children, who grow up in environments that offer more ideal challenges, support autonomy and offer feedback on efficiency, and provide a secure basis, such children tend to have strong approach towards mastery, reflected in practicing freedom and the ability to choose between activities, and interpret their environment, draw information, and seeking opportunities to control their surroundings (Moneta, 2004). Whereas children grow and develop within a family system frame, many researches focused on the importance of relationships' aspects in this system in terms of children's healthy development, (e.g. relationship between mothers and their infants). The available researches focused heavily on this Dyadic Relationship (Landry et al., 2000), as a central relationship in learning self- regulations, this includes attention regulation and future cognitive efficiency. The theoretical cultural and social view, refers to the value of studying child interaction with his caregiver. Vygotsky assured the importance of the social environment as a context where children develop their independent act through experiences they are exposed to, by accompanying a more experienced person (Young \& Hauser-Cram, 2006). He also pointed out to what is called "Zone of Proximal Development" (ZPD); that refer to the ability of the learner to successfully complete the tasks with help gained from more experienced person, i.e. learning through assistance or scaffolding. And hence creat the zone of proximal development that carries with it a cognitive guidance and assistance to the cognitive structure for tasks of learning. Both traditional Vygotskyan theorists (e.g.: Sivan, 1986), and traditional theorists in the field of motivation (e.g.: Brophy, 1999) has observed that this aspect of zone of proximal development, makes it an "inherently motivational zone". The zone of proximal development holds challenges, as the tasks have been standardized in relation to the learner level. In the same time, suitable support is available to ensure completing the task successfully. The help offered by others to the child shall work to assist the child to learn how to work in the difficult tasks, how to control and restrict stress, depression and anxiety, which may rise during achievement of required tasks. Interaction within zone of proximal development leads also to guide learner interests towards the task or the cognitive area, at the same time, where the learner appreciates the knowledge which is appreciated as well by more capable persons (Walker et al., 2010)

It is believed that the emotional social relation between the child and the main caregiver is responsible for establishing the child's belief about the environment responsiveness to his actions (Lamb \& Malkin, 1986). Besides, children who expect positive responses from their caregivers may start to establish a cycle of activities through which they can deal with the environment in reasonable methods, (Heckhausen, 1993; Jennings, 1993). As for the educational interaction technique from the mother, aiming to raise the cognitive development of the child, the researches derived from the socio-cultural theory suggests that the mother attempts to scaffold her child's attempts in a way which we may call "one further step" may encourage the child to persevere in solving problems. Through the help in tasks of moderate difficulty which the child should perform independently, mothers become able to offer help to the current children' skills and challenge the child in order to solve problems which are almost beyond their current level (Young \& Hauser-Cram, 2006).

Goldstein (1999) described the zone of proximal development, as being a socially mediated space which is formed via relationships characterized by sensitivity and confidence. This view of the zone of proximal development as a shared affective zone, has also important motivational implications. The emotional quality and tone of interaction in the zone of proximal development, interest and caring sense displayed by a person may have important impact on child's participation in learning and in the desire to challenge themselves (Walker et al., 2010).

\subsection{Effects of Parental Relationships on the Formulation and Development of Motivation}

Early childhood years are considered the most important period within which the children's motivation is shaped, through raising relationships with their parents. Offering feedback represents the most important issue that parents provide to their child. Parental evaluation starts in early childhood stages and lasts through childhood years, which makes its impact a formative one during child structuring of his/her self- concept. Parental evaluation has many forms; these forms include negative and positive evaluation expressions. Because parental evaluation provides information for the child about the suitability of their actions or outcomes, and whether child efforts and outcomes has achieved parents' expectations, or fall close to it, we can see how parental evaluation impact children internalized standards, and also impact their self- evaluation. At the second year of their life, children start to understand differences between suitable and unsuitable behavior. Around third year of their life, children display their annoyance if anyone exceeds standards. At 20 months, old, the children display unique feelings when their outcomes match, or fail to match standards (Kelly et al., 2000). Such feelings were expected to be a result of internalizing parental standards, through parental feedback. In a study conducted by (Wang, Hwang, Liao, Chen, \& Hsieh, 2011) mastery motivation reliability, in relation to home environment, for infants and toddlers (normally developed children of 2 and 3 years of age) was investigated. Result showed that quality 
of home environment during infancy seems to have a significant effect on mastery motivation in toddlers. On the other hand, in a study conducted by Kelly, Brownell, and Cambell (2000), the relationship between mother discipline and evaluated feedback during second year of life, mastery motivation, and expressing their self-evaluative affect after one year period. The outcomes showed that the evaluative feedback of the mothers and method of discipline at the age of 24 months predicted the child's feeling of shame, persistence and avoidance behavior at 36 months old. Besides the mothers' negative evaluation, at the age of two was correlated to the child's later feelings of shame, especially when feedback has been linked with the child acts or products. On the other hand, the mothers' positive feedback and corrective feedback have been linked to the children's later persistence. Moreover, the mothers who participated in controlling and supporting children's autonomy at the age of two, their children were more likely to avoid challenging tasks at the age of 3 . Also, the findings show that child's feelings of pride at the age of 36 month, was not predictable according to mother's behavior at the age of 24 month.

From this point, we can see that children's standards acquisition was rooted in the first two years of life, although it is an extended process along childhood. Parents assessments make the children aware of how to measure their behavior based on parents' expectations, therefore providing standard that enable children to judge their performance, and set out basis for self-assessment feelings. Moreover, parental assessment may provide the child with ascertain reference on success or failure reasons, (whether success was a result of child's efforts or a result of some attribution or characteristics that the child possesses). The evaluative feedback is not the only route through which the parents may influence child feelings in terms of autonomy and mastery for their environment, in fact the mothers who support autonomous in their children, and who design tasks for maximizing their initiation, are supporting feelings of autonomous and control in those children. Frodi, Bridges, and Grolnick (1985) found out that infants who receive control support from their mothers are classified to be more persevere in the age of 12 months and to be also more efficient in mastery tasks at the age of 20 months compared with infants whose mothers were more controlling and autonomous. Lutkenhaus (1984) found out the same phenomenon; at 36 months old, the mother praise accompanied with satisfaction by smiles correlated positively with their children motivation during tasks, while, the physical interruption and criticizing notes were negatively correlated with child motivation. Also, it was proved that the high control of the mother decreases the pleasure of achieving the task, decreases persistence and sense of autonomy in young children, and correlated with low mastery motivation, avoiding challenge, and low interest in tasks that include achievement (Kelly et al, 2000).

In a study conducted by (Young \& Hauser-Cram, 2006) Interaction between mother and child was tested, whether it can predict mastery motivation (presented in persistence in solving problem tasks) in children aged 3. The results showed that emotional intervention in the relation between mother and child has important benefits for handicapped and premature young children. In another study (Wang, Morgan, \& Biringen, 2014) the longitudinal relationship of emotional exchange between mother and child, at 18 months old, compared with child mastery motivation at 39 months old, was tested. The results proved that the emotional positive exchange had positive longitudinal correlation in the long run with children persistence and efficiency. On the other hand, emotional exchange, which is characterized by, dismissed affects exchange, proved to have negative correlations, at the long run, on children persistence and independent mastery. The outcomes also indicated that the attempts directed towards independent mastery have deep roots in the early emotional interactions between the mother and child.

Among the factors influencing children motivation, the factor that was called "Social facilities in learning contingency" which starts at infancy stage (contingency starts once the child practice an act that may lead to certain influence or outcome; i.e. pressing in the Box bottom in "Jack in the box", and the toy jumps from the box. Here the child links between the action and reaction, due to both incidents contingency). Watson, 1966 paid an attention to "Operant Conditioning of Visual Fixation", where he concluded, through experimental studies, that awareness of contingency indicates human readiness to respond, in adapting manner to contingency situations, and to the human sensitivity in perceiving those situations, when contingency occurs. It is believed that caregivers are pre-programmed to provide such type of contingency experience, and the children as well prefer contingency experiences since early stage, as contingency between behavior and incident works to stimulate the human infant and bring his attention to effective behaviors, which in turn promote mastery. This mastery feeling shall affect Self-evaluation, as successful actions involves positive feedback about self-abilities, which makes the individual independent from external control, and freeing himself to be subjected to selfregulation. From this point, the persistence practiced by the individual to achieve his goal shall become fruitful in spite of Gratification delay. The caregiver is the one who could provide such contingency reaction (e.i. facial and vocal expression) in the infant behavior. It is noticed that humans in general provides such contingency 
experiences, and the accompanying expressions (young chimpanzees aged 1-2 month, which was raised by humans, showed superior responsive behavior, in relation to facial and vocal expression provided by their caregivers). So, it is not surprising that the adult caregiver sensitivity in setting out opportunities to play contingency games with infants shall become the key reasons to predict individual differences in terms of contingency awareness, discovery, manipulative skills and mental development (Heckhausen, 2004).

On the other hand, "Attachment" is considered as a concept that describes the relation between the infant and its caregiver/s. Bowlby (2011) described Attachment as a behavioral system or motive that has external objective in terms of maintaining physical closeness of the infant with its caregiver. Also, it has internal objective as well in terms of achieving felt security. Central to the concept of attachment, is the observable behaviors, and the biological base which Bowlby has referred to as an "attachment behavior", which in turn refer to any behavior from the infant or the young child, aiming to promote physical closeness to his/her caregiver, such as crying, smiling, crawling towards, or clinging to the caregiver. Children were not born with clear preferences about attachment (Breidenstine et al., 2011), but they start with some relationships during their early interactions after birth, and across the early years of life, with their caregivers, specifically when these interactions were consistent For example, it was found that mother-child speech is a collaborative process, during which the mother guides and supports the child during his exploration of emotions and ideas; this could help him/her to organize his/her emotional experiences in a coherent and safe way. According to Thompson, Labile, and Ontai (2003) the shared speech between mother and child, proceed as a mediator in the relation between secure attachment behavior and cognitive representation (Dubois-Comtois et al., 2011).

It is obvious that the infant who enjoys secure attachment relations would probably move away from his parents to discover the world around him, and may try to come closer to the caregiver from time to time, even though he may look to his caregiver to make sure that they are available. Meanwhile, children who suffer unsecure attachment relations are divided into two categories; First category includes the children who suffer inconsistent attachment relations with their caregiver, (the adult may accept him/her in some times and refuse him/her in another). In this case the child may display the behavior of clinging and the desire to be carried. The child from this category wants to receive continuous reassurance from his/her caregiver, which in the main time limits his/her ability to discover his/her world and environment, and also limits his/her experiences, and play opportunities, which will affect his/her overall development. The second category includes children who are confronted with a steady refusal behavior from the caregiver. Those children will learn that adults are not reliable and untrusted, and the relation with them is the source of continuous frustration or even fear). Such children, although will appear uninterested, they will suffer great fear, because they will think that they should care for themselves, while surrounded with an uninterested, and far unsafe world. This feeling of fear will lessen their exploratory behavior of the environment, and accordingly affect all aspects of development, and emotional well-being (Pearce, 2009). These early relationships and its later impact on a child's social world were a subject of excessive study within attachment theory. According to this theory, infants will form mental representations about persons and relations based on child-parent secure early relationships, which in turn, will affect his/her later functions. These mental representations, or what were called "Internal Working Models", were thought to form a filtrate interpretation for the social perception, expectation, and memory, which will cause the young children to approach their new social partners in a biased method, based on secure attachment. This theoretical viewpoint has been supported by a large number of documents, in relation to the link between early secure attachment scales, and later types of relationships, personality, and behavior organization. Recent research on attachment focused on the link between early feeling of security and later self-concept scales, emotional understanding, awareness, and other variables related directly to children's Internal Working Models (Raikes \& Thompson, 2008).

It is worth noting that preferred attachment was seen as a new phenomenon, which could be observed in children between 7-9 months of age, at least under traditional caring circumstances. Protesting on separation from the attachment figure, and the later anxiety with strangers, are behavior indicators, which show that the excessive attachment towards this person was formulated, and towards the end of the first year of life, we can observe the balance between the toddlers' motivation to explore their environment, and their tendency to seek closeness from their caregiver. That is, the toddlers are prepared with newly founded abilities to move independently, and that they are motivated to go far from their caregiver, in order to practice their exploratory behavior. There is also a contrasted balance between his/her willingness, presented in the motivation and seeking to get closer from the caregiver in times of fear, stress, and annoyance. According to this, when the child is near the attachment figure and feel, secure, the system of attachment is not activated, and the child will be motivated to explore his/her environment. But if the child is scared, or threatened, or abused; the attachment system will be activated and the 
motive to explore will diminish or disappear. In this case, the toddler will either seeks closeness with the caregiver, or will be involved in a semiotic behavior to alert the caregiver that he/she is suffering from annoyance. This balance between attachment and exploration could actually be observed when the toddlers and their attachment figures were in interaction with each other. The infants, who show balance between seeking closeness from caregiver and seeking to explore the environment, are described as a securely attached infant. Those children during the "strange situation" appear relaxed with the attachment figure, compared to being silent and conservative with the strange person. During separateness from their caregiver, usually those children decrease exploration, and they usually show annoyance. When they re-encounter their attachment figure, secure attached children will express their annoyance and seeks closeness and comfort with the caregiver (Breidenstine et al., 2011).

In a study for Belsky and Fearson (2002), they concluded that social competency in children aged 3 years, problematic behavior, language, and school readiness could be predicted from attachment interaction, and mother sensitivity (Raikes \& Thompson, 2008).

Sensitive and responsive parental relationship which is consistent with the infant needs, most probably will reinforce secure attachment in their children. Accordingly, it is thought that secure children will develop a working model for themselves, as they belief themselves to be valuable and loved person, and they think of others as responsive to their needs, and vice versa. Unsecure children will see themselves as incompetent, devalued, and they think that others are refusing them, and unresponsive to their needs. All this from within their developed internal working model, and according to parental attachment relationships which could be described as inconsistent and insensitive (Lieberman et al., 1999). These perceptions and believes will permeate the child to go forth into the world with confidence, exploring, and accepting challenges without excessive fears of failure, only then, all aspects of their development and adjustment will be promoted, (Pearce, 2009). In other words, we can say that as a result of mother sensitive and responsive caring, secure children will tend to see themselves as deserving care and others as trusted persons, while as a result of insensitive and unresponsive care, unsecure children will be at risk of seeing themselves devalued, and others as untrusted people (O'connor et al., 2012).

Although attachment researches focused on mother-child relationships, it is now accepted in general that children do formulate several attachment relationships. The "attachment figure" was identified as: the person who provides physical and emotional care and his/her relationship could be attributed with continuity and consistency in the child's life, and he/she are emotionally investing in the child's life. This may include parents (biological, or by adaptation), grandparents, siblings, aunts and uncles, or substitutional caregivers (workers in the field of child care) (Pearce, 2009).

\subsection{Cultural Influences on Attachment and Motivation}

The role of culture and cultural practices from the Vygotskian viewpoint is critical in the construct and formation of motivation. We can realize that cultural practices are repeatable actions or activities that were worked to continue, to change, or to be challenged by different culture members. These practices are valued in local communities who share it, because it is linked with their sense of belonging or identity with specific forms of modernization. It will help in construct learning and thinking activities, and has characterization, and motivational and emotional outputs. Theorists from the Vygotskyian sociocultural approach believe that motivation is internalized during learners' participation in academic practices (as in learning literacy, which is a kind of activities that could be valued in the cultural group). Thus, we could conclude that this emerge from these kind of practices (Walker et.al., 2010). In the light of cross cultural studies, Markus and Kitayama (1991) suggested that individual differences along an individual-collective continuum displayed a self-construal concept that consisted of two components: independent self-construal (the tendency to interpret individual existence as separate from the social context and from the relationships practiced with others), and interdependent self-construal (the tendency to interpret individual existence as integrated with the social group attributed with mutual links and commitment). Persons who belong to western culture possess a self-model which considers the self-independent, while people who belong to eastern culture possess a self-model which considers the self-interdependent. The choice experience is considered characteristic for those who belong to western culture because this provides them with opportunities to seek consistency with previous behavior, and achieving the goal of being unique. The choice experience is less significant in persons who belong to an eastern culture background, because they possess more flexible individual identity across different contexts, and their motivation is weaker in its consistency and uniqueness. From this point of view, all psychological theories about well-being concentrating on autonomy are considered less applicable on members from such collective cultures.

Also several experimental studies (Choy \& Moneta, 2002, Deci et al., 2001, Hayamizu, 1997; Lyengar \& Lepper, 
1999; Kwan et al., 1997; Oishi et al., 1999; Ryan et al., 1999; Sheldon et al., 2001) have provided outcomes with and against the universality of the need for autonomy and control. Although the need for autonomy and control are considered universal, there are cultural differences, linked with self-construal of the meaning and value of autonomy, in addition to components of autonomy which affect motivation and subjective well-being; these cultural differences most probably have various results on motivation study (Moneta, 2004).

Swartz (1994) suggested a theory of "value at social level", this theory also explained the possible reasons behind differences in personality in both western and eastern cultures, eastern cultures value individual's merger in the group, and serious work for maintaining current situation, and showing obedience, and getting along with community culture. On the contrary western culture encourages individual autonomy on private matters, and individuals are encouraged to express their preferences, uniqueness, approaches, and their own feelings. According to eastern culture, individuals should be motivated to consider public well fair (Dekker \& Fischer, 2008). Therefore, cultural differences are expected in family relationships, and in the manifestation of individual motivation.

In some multicultural and multiethnic countries, family differences in raising children are observable according to what Schwartz has noted. As an example, Wood and Graham (2010), studied differences in motivation between African American children, and their western American counterparts, the two research questions were as follows: (1) why there is a clear gap in achievement between African American children and their white peers/and did the motivational aspects partially dependent on ethnical differences, which in turn affect academic outcomes? (2) This question contains an analysis of motivation with the concentration on resilience more than the confrontation of risks, in other words, why many African Americans who develop in high risk environment, have good academic performance? Are there any motivational factors which could explain partially their academic resilience in the face of adversity? As developmental studies show, many African Americans, displayed good performance on various motivational indicators, including mainstream educational values, school engagement, their approach towards quality, academic self-concept. These positive motivational outcomes usually develop in the presence of several risk factors, which contribute in shaping a powerful academic approach and meanwhile maintain it as a separate entity for African Americans. Most theoretical studies, concentrate on interpersonal process (e.g. individual need for achievement, objectives, attributions), while the least attention was spent on social context which motivation emerges from within. For African Americans, adaptive culture may include several factors that parental practices try through it to neutralize ethnical bias on children development as a kind of racial socialization (Wood \& graham, 2010). Therefore, raising conditions that are affected by cultural factors, and in turn will affect individual and family, could have an impact on motivation manifestation and power.

As for attachment, it was defined as a mono and mutual (between two persons) approach process, even though there is recognition of the existence of different caring systems were several caregivers are sharing different responsibilities, nevertheless, many attachment-researches consider the original Bowlby's model and ideas about mother-child relationship as the foundation in attachment construction. This mono view for young humans and their mothers was based on a primitive model for Rhesus Macaques, which is characterized by a specific role for the mother in caring for youngsters, which in turn was used as an evolutionary basis. Meanwhile, there is another primitive model which includes different caring management, this model is for Cottontop Tamarins, who depends much more on distributing the responsibility of youngsters caring; and Capuchin Monkeys, which do not differ in its activities from mothers than those of siblings, or other adults who are not linked with the youngsters. What was found actually, is that parenthood in more than 300 primitive genres, which may greatly vary according to Fairbanks (2003), depending on social systems and parental strategies in addition that this will vary according to context, which defeat the hypothesis of having only one natural model (Keller, 2014).

One of the main problems in attachment studies, and parental indicators influencing it, is that attachment studies was developed broadly on American and European infants from middle class, and that Ainsworth original hypothesis about mother sensitivity during usual interaction between mother and child, is linked with secure attachment in infants. All these have been drawn from a number of theories conducted on children from the same social class (for example: Egeland \& Fareber, 1984; Pederson et al., 1990). (Lounds et al., 2005). A few empirical approaches for assessing attachment (which includes behaviors) across cultures, didn't reflect the potential concept of culture, For example, Posada et al. (1995) who compared experts and mothers in China, Colombia, Germany, Israel, Japan, and U.S.A., in their definition of secure attachment according to attachment Q-sort description. The result shows that concepts of both experts and mothers across cultures on attachment were approximate. It is worth noting that the cultures in these studies (such as: Vaughn \& Waters, 1990) were considered synonymous to country which is incorrect, because most of the experts have passed through a kind of 
western education, which explain the approximates of their view with attachment theory. In addition, most participant mothers averaged 31 year in age, and received a formal education, which lasts about 12.5 years, and they have a number of children ranged about 1.9 child. This sociodemographic profile presents exactly middle class groups in any society; those people are holding similar objectives in relation to child care and in relation to values. This matter could be observed across many countries. Nevertheless, the results varied between samples from different countries. This study and many others, prove that cultural contexts usually were referred to as "cultural differences" when no other explanation could be found. According to this, there is no coherent concept for culture which can guide such studies. Greenfield and Keller (2004) suggested a definition for culture as a value, standards, beliefs (the ideal aspect of culture), actions and behaviors (behavioral aspect of culture), which is shared by people who lives in the same social environmental context; noting that countries could include several cultural media (Keller, 2014).

Despite the familiarity of studying attachment from the view point of duality of the relationship between mother and child based on the western view point, and the tendency to generalize this view to other societies, it was found that despite the recognition of multiple attachment figures by theorists, including Bowlby, the majority of studies remain focusing on duality of relationship between mother and child. In addition, researches continue to emphasis western cultures. "western children often have less access to and less stable allomaternal attachment figures than what is commonly experienced by children cross-culturally" (Mehan \& Hawks, 2014). According to this, it is noticeable that recently, there is a vast majority of studies exploring the role and significance of non-maternal attachments in formatting children's internal working models, and the developmental outcomes. It is possible to say that the circumstance during which attachment was developed according to Bowlby's view point is well matched with west perception of how mothers should raise their children. Nevertheless, in several parts of the world, including west and western culture, we can notice that on a daily basis mothers are sharing their youngsters care with other helpers, whom they can depend on (non- maternal caregivers), this could be seen from an early stage of the child's life. Which may show how could humans be considered as cooperative breeders. This cooperation doesn't mean that mothers are not the first caregiver for their children, or that they aren't the first attachment figure. We may note that while the focus of child development and attachment research was on duality of mother-child relationship, this pure duality does not exist separately in reality, it is actually included within a bigger social network, and is influenced by it. Accordingly, recent approaches from Meehan \& Hawks viewpoint sheds light on the role of several persons, who play the role of mothers (allmothers), and who develop attachment relationship with infants. Anthropologists investigated the effects of the existence of other persons on human reproduction and child development. Results of these researches show that human mothers could not care successfully for her children in an independent manner. And those mothers are in need of allomaternal investment; this successfully exists across cultures. This kind of allomaternal caring with help of non-parental others in raising the slow developing human youngsters (compared to other species) was not possible if the mother has to do it by her own, or with the help of the father only (Meehan \& Hawks, 2014).

Based on all what precede, we can conclude that depending on several persons as helpers of the mother in caring for her children, could be common in several cultures. Children could build attachment relationships with more than one person at the same time. In Saudi society, which belongs to eastern culture, a traditional life style has lasted for a long time, matched with the idea of cooperation in children rearing within the extended family system. But recent years, and with modern civilization, after oil exploration, many aspects of the Saudi life have developed greatly, and accordingly great development in family relationships was observed as a result.

The local production development during the last four decades has great impact on the developmental rates in the Kingdom, which was reflected on the levels of education and health, and in consumption rates, life styles, and in wellbeing levels. This wellbeing reflected on, as was seen in other populations in the world, on demographic variables and on population structure in the kingdom. The Kingdom of Saudi Arabia is going now through an obvious demographic change as a result of previous mentioned development, represented in an openness to the world, and acceptance for several sociological variables, which was not known before, which in turn resulted in the openness to the market labor of domestic workers, coming from different parts of the world, that all community levels benefited from (Al Saqqa, 2012)

In the Kingdom of Saudi Arabia, the phenomenon of domestic workers was considered linked with some social stress facing Saudi families, after economic and political changes that the Kingdom has gone through in the last decades, and its impacts, like the large spaces in Saudi houses. The Saudi houses became bigger, and concepts of cleanliness has progressed, aesthetic values, and house decoration became needed more in Saudi families, accordingly ways of house managing, in addition to the need of what was called " civilized services " as a result of big numbers of children, and the spread of women education, and her engagement in the labor market, which 
leads to additional efforts needed in serving the house and family, which wives could not afford because it represents a heavy burden and social stress, which make the need for the domestic workers greater than before, in cleaning, in managing, and organizing houses, and caring for children specially infants (Al Khoudairy, 2004).

In a study conducted by Al Otaiby (2014) about the effect of foreign domestic workers on the child socialization in the Saudi society, results show that participants have agreed on several implications of having foreign domestic worker at home, and in caring for children. These implications included weakening the relation between the child and his/her parents. The study also showed that the dependency of Saudi families on foreign domestic workers in several tasks related to child care include: child hygiene - organizing his/her time of sleep presenting healthy foods - giving him/her medicine in time of illness - bowel training - playing with the child sharing him/her in time of leisure - accompany him/her for walks - helping him/her in choosing dolls and play materials - awakening him/her for school - helping children in learning English language - buying school materials - tacking children to school - supervise children in doing their homework (Al Otaiby, 2014). This great dependency on domestic workers in Saudi families in meeting children needs and caring for them, may mean the transmission of child attachment with the mother, to an attachment with the domestic worker (most probably the domestic worker is a foreigner, her literacy knowledge with mother tongue is limited, and speak it with an accent). In addition, it is possible that the relation between the domestic worker and the child could discontinue for many reasons, such as returning to her own country or changing to go work with another family. This matter could have a reflection on the child, who constructed a secure relationship with the domestic worker, and became dependent on her in many tasks, as shown in some studies (for example Al Otaiby, 2014), which will impact his/her secure attachment, and on his/her mastery motivation, and persistence in challenging tasks. From this point, the current study aims to specify the effect of secure attachment with mother on mastery motivation in preschool children from Riyadh city, and also aims to identify the effect of dependency on additional caregivers on child (represented on dependency on domestic workers as a spread-out phenomenon in the Saudi society, nevertheless it does not include all families) on mastery motivation of the same preschool children from Riyadh city. Specifically, the present_study that is interested in answering the following main question:

To what extent mastery motivation with all its dimensions, would be affected with attachment relationships (secure/unsecure) with the mother, and (dependency/non-dependency) on domestic workers in the Saudi society?

This main question could be divided into the three following sub-questions:

1) To what extent mastery motivation in children, with all its dimensions, would be affected by attachment relationships (secure/unsecure) with the mother in the Saudi society?

2) To what extent mastery motivation in children, with all its dimensions, would be affected by (dependency/non-dependency) on domestic workers in the Saudi society?

3) To what extent mastery motivation in children, with all its dimensions, would be affected by the interaction between attachment (secure/unsecure) with the mother and the (dependency/non-dependency) on domestic workers in the Saudi society.

\section{Methodology}

The descriptive comparative method was used in this study, where two groups of children from families depending and non-depending on domestic workers in caring for children were compared to each other. In addition, there was another comparison between those children who are described as secure attached and those who are unsecure attached from both groups (depending and non-depending on domestic workers).

\subsection{The Study Sample}

The present study focused on determining the children attachment types with mother, specifically as reflected on child usual behavior as a substitution to the "strange situation", because it is difficult to manage suitable condition for such procedure in the context of Saudi society, where it is difficult to receive children and their mothers in university research centers. The study group consists of 183 preschool children, ranged in age from 3.5 to 6 years, attending several kindergartens in Riyadh city. The attachment type with mother was identified according to a close family member (usually the mother or close relatives, such as big sisters or aunts) answer to the following questions:

- Does the child seek closeness with his mother when he is annoyed?

- Does the child get along with strangers easily and talk to them openly?

Those two questions were constructed on the basis of attachment theory indicating that the secure attached child could move independently from his caregiver in order to explore his/her environment, and at the same time, there 
is a contradictory balance for this desire, represented in the motive to seek proximity from the attached figure in times of fear, stress, or annoyance, which means that, while the child is on the presence of the attached figure and feels secure, the attachment system will deactivate, and the child will be motivated to explore his/her environment (physical and human environment). But whenever the child is scared, or threatened, or abused, the attachment system will be activated, and the motivation of exploration will diminish or disappear, and instead of that, the child will either seek approximate with his caregiver, or engage in a semiotic behavior to alert the caregiver to his/her annoyance (Breidenstine et al., 2011).

Additionally, the infants are formatting mutual representation about people and relationships based on parent-child early relationships, which will affect his/her later functions (whether this relation was secure or unsecure). This mental representation was called "Internal Working Models" which was believed to form a filtrated interpretation for his/her social perception, expectations, and memory which will result in the way young children will approach their new social partner in a biased way, according to their type of attachment (Raites \& Thompson, 2008).

In addition to the past two questions, we added another two questions about the family dependence on domestic workers as follows:

- Does the family depend on domestic workers in house holding?

- Does the family depend on domestic workers in caring for children and in meeting their needs?

Responding with yes on the first two questions means that the child is securely attached to his/her mother, while responding on one of these two questions or both of them with no will mean that the attachment relationship with the mother is unsecure. And for the latter two questions related to dependency on domestic workers, responding to the second question with yes will indicate that the family depends greatly on domestic workers to the extent that they depend on them in caring for children and meeting their needs. It is worth noting that some Saudi families are depending on domestic workers only in household managing, but not in caring for children and infants, accordingly it is hypothesized that the domestic worker will not be considered as an attachment figure for the child, as is the case with other family members. On the other side, there are families that depend on domestic workers in caring for children and meeting a large number of their needs as was indicated before (in Al-Oteibi study). From this point, positive responding to the second question was considered as an indicator to the inclusion of the domestic worker among the attached figures for the child.

Based on responding to the four questions, the children were divided into four groups as follows:

- The group of securely attached children to their mothers, whose families are not depending on domestic workers in child care $(\mathrm{N}=48)$

- The group of securely attached children to their mothers, whose families are depending on domestic workers in child care $(\mathrm{N}=40)$

- The group of unsecured attached children whose families are not depending on domestic workers $(\mathrm{N}=61)$

- The group of unsecured attached children whose families are depending on domestic workers $(\mathrm{N}=34)$.

\subsection{Procedures}

A group of volunteered students from education college of King Saud University distributed a questionnaire to volunteer mothers of preschool children aged 3.5 -6 years. The mothers or close relatives who accepted to participate in the study were asked to fill up the DMQ17 questionnaire, and responding to the four questions related to the type of attachment and the extent of dependency on domestic workers in the child's family. A $2 \times 2$ Anova table was conducted ( 2 attachment types $x 2$ state of dependency on domestic workers), on questionnaire results on the four mentioned groups

\subsection{Tools}

To obtain the study aims, the dimensions of mastery questionnaire DMQ17 for George Morgan (Morgan, et al. 2009) was conducted, after translation to Arabic language and representing to pilot participants to reassure that the meaning of items was clear and understood.

The DMQ17 questionnaire is assessing mastery motivation in children under the age of 6 years, so it provides information about the actual and observable children performance in daily life and not through an experimental situation, which could not reflect their usual behavior. The questionnaire is applied by mothers or close relatives, due to the easiness of understanding their items and the ability to respond to it easily. And thus, it was considered a good tool for rating child's mastery motivation, by persons who are close to the child on a daily basis, and their 
observation does not depend on one or two situations of the child's life, which makes their ratings more valid.

George Morgan depends in his assessment for mastery motivation on several aspects: Instrumental aspect, which represents all types of persistence as a way of solving problems - and expressive aspect, which is usually referred to with mastery pleasure, this reflects child's expressing of positive feelings during his task oriented behavior, or after achieving a goal or solving a problem (as in expressing pride or shame). This aspect includes manipulating objects and physical tools, but it includes also actions oriented towards people, the latter was called social mastery motivation, where it includes children's attempt to start interacting with others, and maintaining this relation and affect it. Another aspect was added to mastery motivation, which is gross motor aspect. The questionnaire includes several subscales for several components of mastery motivation. These subscales are: persistence towards objects - social persistence with adults - social persistence with children - gross motor persistence - mastery pleasure - total competence - negative reaction towards failure. From these subscales, the total persistence was calculated and also total mastery motivation. The total persistence score was calculated from the sum of subscales (persistence towards objects - social persistence with adults - social persistence with children - gross motor persistence), while the total score of mastery motivation was calculated from the sum of the following subscales: persistence towards things - social persistence with adults - social persistence with children - gross motor persistence - mastery pleasure (Morgan, et al. 2009).

The validity of questionnaire was calculated by presenting the questionnaire to several expert faculty staff ( $\mathrm{n}=5)$, where they agree that the questionnaire items represents motivation dimensions as observed in children behavior and that the items included are clear and easy to understand. The internal consistency coefficient Alpha-Cronbach was used to calculate reliability of the questionnaire, the reliability was $(0.785)$.

\section{Results}

The first question of the study was: To what extent mastery motivation in children, with all its dimensions, would be affected by attachment relationships (secure/unsecure) with the mother in the Saudi society?

Table 1. Means and standard deviation of children scores on DMQ 17 Scale

\begin{tabular}{ccccccccc}
\hline Scale dimensions & $\begin{array}{c}\text { Children groups of } \\
\text { attachment variable } \\
\text { (secure/unsecure) }\end{array}$ & N & M & SD & $\begin{array}{c}\text { Children groups of depending } \\
\text { on domestic workers }\end{array}$ & N & M & SD \\
& Total secure attachment & 88 & 3.325 & 0.853 & Totally dependent & 73 & 3.228 & 0.1873 \\
\hline Persistence towards & Total unsecure attachment & 95 & 2.937 & 0.713 & Totally not dependent & 115 & 3.055 & 0.749 \\
objects & Total secure attachment & 88 & 4.566 & 0.856 & Totally dependent & 73 & 3.855 & 1.57 \\
Social Persistence & Total unsecure attachment & 95 & 3.277 & 91.5 & Totally not dependent & 115 & 3.511 & 0.833 \\
with adults & Total secure attachment & 88 & 4.075 & 2.232 & Totally dependent & 73 & 3.554 & 0.957 \\
Social Persistence & Total unsecure attachment & 95 & 3.184 & 0.865 & Totally not dependent & 115 & 3.661 & 2.083 \\
with children & Total secure attachment & 88 & 4.148 & 2.805 & Totally dependent & 73 & 3.678 & 0.940 \\
Gross motor & Total unsecure attachment & 95 & 3.495 & 1.693 & Totally not dependent & 115 & 3.891 & 2.882 \\
persistence & Total secure attachment & 88 & 3.871 & 0.787 & Totally dependent & 73 & 3.660 & 0.994 \\
Mastery pleasure & Total unsecure attachment & 95 & 3.310 & 0.827 & Totally not dependent & 115 & 3.515 & 0.756 \\
Total competency & Total secure attachment & 88 & 3.572 & 1.474 & Totally dependent & 73 & 3.298 & 0.854 \\
& Total unsecure attachment & 95 & 3.102 & 0.841 & Totally not dependent & 115 & 3.347 & 1.396 \\
Negative reaction & Total secure attachment & 88 & 3.587 & 0.738 & Totally dependent & 73 & 3.004 & 0.934 \\
towards failure & Total unsecure attachment & 95 & 3.237 & 2.731 & Totally not dependent & 115 & 2.694 & 2.440 \\
Total persistence & Total secure attachment & 88 & 17.658 & 8,927 & Totally dependent & 73 & 15.813 & 8.675 \\
Total mastery & Total unsecure attachment & 95 & 13.825 & 2.605 & Totally not dependent & 115 & 15.498 & 5.108 \\
motivation & Total secure attachment & 88 & 22.732 & 7.578 & Totally dependent & 73 & 19.332 & 7.491 \\
& Total unsecure attachment & 95 & 17.393 & 4.185 & Totally not dependent & 115 & 19.555 & 5.632 \\
\hline
\end{tabular}

Table 1 shows the means and standard deviations of children scores on DMQ 17. The highest score means of children across all subscales were for the secure attached children in comparison with unsecure attached children. In the dimension of persistence towards things, the means scores were (3.325 for secure attached children against 2.937 for the unsecure attached), social persistence with adults was (4.566 for secure attached against 3.277 for unsecure attached) - social persistence with children (4.075 for secure attached against 3.184 for unsecure attached) - gross motor persistence (4.148 for secure attached against 3.495 for unsecure attached) - mastery 
pleasure (3.871 for the secure attached against 3.310 for the unsecure attached) - the total competence ( 3.572 for secure attached against 3.102 for unsecure attached) - negative reaction towards failure ( 3.587 for secured attached against 3.237 for unsecure attached) - and as for the scales of total competence and total mastery motivation, the means of scores were: (17.658 for secure attached against 13.825 for unsecure attached) and (22.732 for secure attached against 17.393 for the unsecure attached).

All these scores prove that there was a relationship between type of attachment with mother (secure/unsecure) and mastery motivation with its all dimensions, as was assessed by DMQ 17.

According to socio-cultural theory (Brunner, 1986; Vygotsky, 1993), it was hypothesized that mother Attempts to provide what is called "one step further" of scaffolding may encourage children to engage and perceive in problem solving. And through the help in moderate challenging tasks, where children are encouraged to achieve it in their own, and the mother role was to support children's recent skills, and challenging children in solving problems in a level that are exactly beyond their recent developmental level. This support and scaffolding is in continuous change, as the child becomes more competent (Young \& Hauser-Cram, 2006).

In addition, Ainsworth original hypothesis about the relation between mother sensitivity during her early usual interaction with the child, and secure attachment in infants, which was derived from observation for children who belonged to western culture (for example: Egeland \& Farber, 1984; Pederson et al., 1990) seems to be true also in relation to eastern cultures. Even when attachment was studied comparatively on several cultures, some belongs to eastern context, and the other to the western context (for example: Posada et al., 1995), in relation to mother concepts about secure attachment, they found great proximity between members of these cultures, in relation to this concept. Although there is differences between cultures in considering the space of freedom permeated to their members in both eastern and western cultures, or in other word, individual and collective cultures (Moneta, 2004), and the actual existence of partnership in child care with other helper in the eastern culture compared to the western culture (at least theoretically or ideally according to the view of each culture, this does not eliminate the idea of the mother as being the first caregiver of her youngsters, and as a result, she is the first person whom the child is attached with.

As for hypothesis about the duality of relationship between mother and child, and on an actual base, this duality does not exist separately from the bigger social network (Meehan \& Hawks, 2014).

The second question: To what extent mastery motivation in children, with all its dimensions, would be affected by (dependency/non-dependency) on domestic workers in the Saudi society?

Results in table (1) show that in relation to dimensions of mastery motivation in the two groups of children (dependent/non-dependent) on domestic workers, significant differences were found between children score means in the two groups of children in favor of children from families dependent on domestic workers, on the following subscales: persistence toward objects (3.228 against 3.055) - social persistence with adults (3.855 against 3.511) - mastery pleasure (3.660 against 3.515) - negative reaction towards failure (3.004 against 2.694) - total persistence (15.813 against 15.498).

While results in table (1) show that mean scores of children non- dependent on domestic workers was bigger on the following subscales: social persistence with children (3.661 against 3.554) - gross motor persistence (3.891 against 3.678) - total competency (3.347 against 3.298) - total mastery motivation (19.555 against 19.332). Which indicated that dependency or non-dependency on domestic workers was not the effective factor in subscales of mastery motivation?

When reflecting on the first question results related to attachment, data in the recent study indicated that the critical effect was for attachment relationship with the mother on all mastery motivation dimensions; one can imagine the potential reasons behind non-clearance of the dependence/non-dependence on domestic workers' factor.

Maybe the overlap between the attachment effects (which appear to be the most effective variable), and the dependence/non-dependence on domestic workers' variable, could have an effect on such results. In other words, the families who are dependent to some extent on domestic workers, with the existence of secure attachment with mother, which can explain that depending on others in helping the mother in child care, is ineffective variable on mastery motivation, because such mastery motivation was affected in the first place by the secure attachment with mother. Such conclusion was based on the results of the recent study, is in congruent with the critique of LeVine (2014) to Bowlby's original model, who claims that the duality model between mother and child, is a fixed model, applies to all humans, as it is considered genetically transmitted. In this point LeVine suggested that researchers in attachment field was ignore, exclude, and distort cross-cultural clues which indicate 
the existence of greater variation between humans in relation to their maternal behavior, and infant emotional resilience, which could result in ruining this claimed model. And that Bowlby's claim about the western way in showing the mother her love to her child, is not as he claimed that it is as important as vitamins for child health, but it could be as important as other minerals, which have the same value, and it could format a healthy substitute for meeting child's needs (LeVine, 2014).

Table 1 indicate that no significant differences were found between the score means of children dependent and non-dependent on domestic workers in relation to all subscales of DMQ 17.

The answer to the third question could shed more light on the effect of depending/non-depending on domestic workers in its reaction with the attachment variables.

The third question was as follows: To what extent mastery motivation in children, with all its dimensions, would be affected by the interaction between attachment (secure/unsecure) with the mother and the (dependency/non-dependency) on domestic workers in the Saudi society.

Results in Table 2 show significant differences in relation to the interaction between the two variables (attachment and dependency on domestic workers) on the following subscales: persistence towards objects $(0.01)$ - social persistence with adults $(0.05)$ - mastery pleasure $(0.01)$. while no significant differences were found on the following subscales: social persistence with children, gross motor persistence - total competence - negative reaction towards failure - total persistence - total mastery motivation.

Table 2. Results of 2x2 ANOVA table (attachment $\mathrm{x}$ dependence on domestic workers)

\begin{tabular}{|c|c|c|c|c|}
\hline Scale dimensions & source of Variance & mean squares & $\mathrm{F}$ & Significance \\
\hline \multirow{3}{*}{ Persistence towards objects } & attachment (secure/unsecure) & 8.011 & 13.4 & 0.01 \\
\hline & Dependence/non-dependence on domestic workers & 0.723 & 1.209 & no significance \\
\hline & Attachment*dependence & 3.504 & 5.862 & 0.01 \\
\hline \multirow{3}{*}{ Social persistence with adults } & attachment (secure/unsecure) & 29.27 & 40.59 & 0.01 \\
\hline & Dependence/non-dependence on domestic workers & 2.786 & 3.68 & No significance \\
\hline & Attachment*dependence & 3.34 & 4.63 & 0.05 \\
\hline \multirow{3}{*}{ Social persistence with children } & attachment (secure/unsecure) & 34.181 & 12.156 & 0.01 \\
\hline & Dependence/non-dependence on domestic workers & 1.749 & 0.622 & No significance \\
\hline & Attachment $*$ dependence & 0.926 & 0.329 & $==$ \\
\hline \multirow{3}{*}{ Gross motor persistence } & attachment (secure/unsecure) & 24.342 & 4.588 & 0.05 \\
\hline & Dependence/non-dependence on domestic workers & 3.833 & 0.723 & No significance \\
\hline & Attachment $*$ dependence & 4.411 & 0.643 & $==$ \\
\hline \multirow{3}{*}{ Mastery pleasure } & attachment (secure/unsecure) & 18.767 & 29.600 & 0.01 \\
\hline & Dependence/non-dependence on domestic workers & 0.202 & 0.318 & No significance \\
\hline & Attachment $*$ dependence & 4.637 & 7.318 & 0.01 \\
\hline \multirow{3}{*}{ Total competency } & attachment (secure/unsecure) & 5.559 & 7.794 & 0.01 \\
\hline & Dependence/non-dependence on domestic workers & 0.474 & 0.332 & No significance \\
\hline & Attachment $*$ dependence & 0.602 & 0.422 & $==$ \\
\hline \multirow{3}{*}{ Negative reaction towards failure } & attachment (secure/unsecure) & 34.511 & 9.108 & 0.01 \\
\hline & Dependence/non-dependence on domestic workers & 1.853 & 0.489 & No significance \\
\hline & Attachment $*$ dependence & 8.167 & 2.155 & $==$ \\
\hline \multirow{3}{*}{ Total persistence } & attachment (secure/unsecure) & 735.209 & 17.384 & 0.01 \\
\hline & Dependence/non-dependence on domestic workers & 0.650 & 0.15 & No significance \\
\hline & Attachment $*$ dependence & 36.088 & 0.853 & $==$ \\
\hline \multirow{3}{*}{ Total mastery motivation } & attachment (secure/unsecure) & 1000.225 & 27.532 & 0.01 \\
\hline & Dependence/non-dependence on domestic workers & 24.680 & 0.679 & No significance \\
\hline & Attachment $*$ dependence & 134.981 & 3.715 & $==$ \\
\hline
\end{tabular}

By reviewing Table 1 it is obvious that in such dimensions, the mean scores of children dependent on domestic workers, was higher than the mean scores of children non-dependent on domestic workers, where their mean scores on these subscales were as follows: persistence towards objects (3.228 against 3.055) - social persistence with adults (3.855 against 3.511) - mastery pleasure (3.660 against 3.515). In all these subscales, mean scores were greater in favor for dependent children on domestic workers against those who are non-dependent. 
In other words, results of the recent study indicated significant differences on these specific scales in favor of the dependent children on domestic workers, while differences were found on the other subscales, but these differences were not significant (these dimensions were: negative reaction towards failure - total persistence). Such results were surprising, because of the dependency of this group of children on domestic workers, in meeting their needs, makes them less independent, and less persevere. But these results indicated the opposite, at least in these three subscales.

In general, such results was evident about the validity of what several researchers have discussed (e.g.: Keller, 2014; LeVine, 2014), about the existence of clues indicating that the care of additional helper with the mother in rearing children, is a common thing among humans in several cultures, and among other species, like several kinds of monkeys. And that human specially tends to play contingency games, compared to other species, even when rearing animal's youngsters. Such contingency usually is accompanied with reactions including facial and vocal expressions, which make even Chimpanzee youngsters raised by humans, showing superior responsive behavior, in relation to the facial and vocal stimulus from the human caregiver (Heckhausen, 2004).

On the other hand, the reason behind the high scores for these group of children in the dimensions of persistence with objects - social persistence with adults - mastery pleasure, may be specifically a result of the effects of the foreigner domestic workers, in their caring for children in a way that match with their original culture (It is observed that the majority of the foreign domestic workers, is from Asia. Although they belong to an eastern and collective culture like the Saudi society, these cultures are valuing greatly the persistence in work), which may explain the high scores among children dependent on domestic workers in the persistence with objects, and mastery pleasure dimensions. In addition, we concluded that because these workers are available for the children, and willing to meet their needs, could explain their high scores on the dimensions of social persistence with adults, compared to non-dependent children.

\section{Conclusion}

The recent study focused on identifying the impact of attachment relationships with the mother and the dependence on domestic workers in the Saudi society context, (where a lot of families depend on domestic workers within favorable economic and social circumstances), on mastery motivation in a sample of Saudi children who belonged to families depending on domestic workers in one group, and in families who do not depend on domestic workers especially in caring for children in the second group. Results show that early attachment relationships with the mother have a critical impact on the development of mastery motivation in all its dimensions which reassure that the mother's sensitivity towards her child in early stages of life is considered vital for the child's relation with his/her physical and social environment, this result is partially congruent with some theoretical components of Jhon Bowlby, about mother sensitivity for her child's needs. This sensitivity was considered the foundation which according to it, the child will assess his/her later or new social relationships, while the child will construct his/her expectations in the light of his/her mental representation of his/her previous relationships with the mother, in addition to its effects on the child's self-concept (Raikes \& Thompson, 2008). In addition to what the results have revealed about the unrealistic idea of the child's depending exclusively on his/her mother in meeting his/her developmental needs, the result shows that no effects were found for the variable of depending/non-depending on domestic workers in child care on mastery motivation with all its dimensions. This means that seeking help in child care is not considered effective in itself, and that the powerful impact is for the attachment relationship with the mother. This result is congruent with recent visions about attachment theory, which notes that mothers only, or even with the help of fathers, could not care for her children and raising them without the help of others, in the light of human long childhood, and slow maturity of the human child (Meehan \& Hawks, 2014). In other words, attachment with mother is considered as a significant variable in the development of mastery motivation dimensions, while the variable of depending/non-depending on domestic workers did not prove any effects at least on the development of some mastery motivation dimensions, which demonstrate that the critical factor in the attachment formation is the early stable relationship between mother and child, whether the mother is depending or not depending on domestic workers as helpers in child care.

Meethan and Hawks (2014) have discussed this point, explaining that in daily life in several parts of the world, east and west, mothers are sharing child care with others from an early stage of child's life, and that this cooperation does not mean that mothers are not the first caregivers of their children, or that they are not the first attachment figure for her child. The presence of other helpers for the mother in her child care does not undermine the strong early relationship, if it was already formatted, and that this cooperation from others in child care does not diminish the actual attachment relationship between mother and child, nor substitute it in any way, according to the current study results. 


\section{Recommendations}

This study along with other studies (e.g.: O'connor et al., 2012, Pierrehumbert et al., 2000; Raikes \& Thomspon, 2008), generates evidence that attachment relationship (especially the mother) is considered essential for human development, Motivation, willingness to learn, and persistence in the face of problems, which appear as a logical result of such relationship, which forms a launchpad for the child development as well. At the same time, there is nothing that prevents having other assistance in caring and in raising the child as long as the attachment has been formulated. According to this, and within the Saudi context mentioned before in this study, which explain the reasons behind the increasing reliance on domestic workers in the Saudi society, this study set out the following recommendations:

1) Providing parenthood education to Saudi families (through TV programs, booklets, and raising awareness courses) that discuss the importance of establishing early relations with their children, which exceeds providing them with physical care and meeting children's basic needs, to the emotional attachment relationship with identifiable people whose presence is crucial for the child's emotional security.

2) With increasing women employment in the Saudi society, and filling jobs that where for a long period dominated by men i.e. doctor, engineer, University professor, there is a need to legislate new laws allowing mothers to take a sabbatical from work or work part-time, allowing them to settle and spend more time with their children without unnecessary stress.

\section{Suggestions}

The current study sheds light on some effects related to attachment relationship in the early childhood years. On the other hand, it is proved that children establish many attachment relations in the same time during such years and afterwards. So, it is essential to study the other attachment relations such as father and grandfathers and it's probable impacts on some developmental aspects (such as psychological resilience development, internal control), and in the same time studying the personal factors of adults who offer care for children, which may affect the attachment relations with children. Although, such research has been conducted on the Saudi environment, but caution must be taken on generalizing such results on the entire Saudi context of the study sample which was selected from (the capital city of Riyadh), which means that many of the study participants have acquaintance with Western culture. It is worth mentioning that the majority of the participated children were enrolled in kindergartens and most parents received intermediate or higher education. But is hypothesized that working with a group of children, from different regions of the Kingdom, like in the boardered areas, who are not benefiting from such facilities, may generate different results? Therefore, it is useful to broaden the area of conduction in the future to include such distanced areas from western culture, which may in turn reflected on parent's preferences, values, and practices of parenthood, on children personality. From this point, the researchers suggest that the assessment of attachment relationship in participant children, should be accompanied with an ethnographic study for the nature of the family relationships in such distanced areas, and also in the mobile tribes in such regions, to investigate their vision and beliefs about 1 nfant and toddler needs, and at what time of children life they consider them distinct persons, who possess specific personality and awareness, and accordingly they deserve to get attention and support, in the light of what David F. Lancy has noted, that the majority of communities consider infants and even older children, as not a person in the full meaning (Lancy, 2014).

Such ethnographic studies also need, to be integrated with other types of researches; i.e. neurobiological research The aim of such studies is to investigate about the infant secure attachment in the distanced areas in the Saudi society, and in Bedouins mobile community. Such studies, could reveal the nature of some psychological symptoms indicating that the infants are suffering from a stressful situation, even in the absence of facial expressions (as is the case in some societies that don't welcome the open expressiveness of annoyance or not welcoming the strangers), for example, increasing in heart beats, or the increase of Cortisol hormone, if there is any increase to be recorded, similar to what was observed in some cross cultural studies(e.g. Keller et al., 2011), which was discussed in this research.

Due to the results of the current study, and on what has been mentioned in the recommendations, it is suggested to apply several empirical studies, that includes guiding programs for parents, about the importance of building a secure attachment relationship with their children, and how to maintain such relationships, especially those families who lack the awareness of children's needs of secure attachment relationships in their early years.

\section{References}

Al-Oteibi, L. (2014). Foreign workers effect on Child Social Raising in Saudi House (Field Study). Thesis, 
Social Studies Department, King Suad University, K.S.A.

Belsky, J., \& Fearon, R. (2002). Early attachment security, subsequent maternal sensitivity, and later child development: Does continuity in development depend upon continuity of caregiving? Attachment \& human development, 4(3), 361-387. https://doi.org/10.1080/14616730210167267

Bowlby, M., \& Barušs, I. (2011). Percieved Parental Attachment and Achievement Motivation. Psychological reports, 109(3), 940-948. https://doi.org/10.2466/09.10.21.PR0.109.6.940-948

Breidenstine, A., Bailey, L., Zeanah, C., \& Larrieu, J. (2011). Attachment and Trauma in Early Childhood: A Review. Journal of Child \& Adolescent Trauma, 4(4), 274-290. https://doi.org/10.1080/19361521.2011.609155

Brophy, J. (1999). Teaching. International Academy of Education and the International Bureau of Education.

Burnner, J. (1986). Actual minds, possible worlds. Cambridge, MA: Harvard University Press.

Cerasoli, C., \& Ford, M. (2014). Intrinsic Motivation, Performance, and the Mediating Role of Mastery Goal Orientation: A Test of Self-Determination Theory. The Journal of psychology, 148(3), 267-286. https://doi.org/10.1080/00223980.2013.783778

Choy, W., \& Moneta, G. (2002). The Interplay of Autonomy and Relatedness in Hong Kong Chinese Single Mothers. Psychology of Women Quarterly, 26(3), 186-199. https://doi.org/10.1111/1471-6402.t01-1-00002

Deci, E., \& Richard, R. (1985). Intrinsic motivation and self-determination in human behavior (p. 86). New York and London: Plenum Press. https://doi.org/10.1007/978-1-4899-2271-7

Deci, E., Ryan, R., Gagné, M., Leone, D., Usunov, J., \& Kornazheva, B. (2001). Need Satisfaction, Motivation, and Well-Being in the Work Organizations of a Former Eastern Bloc Country: A Cross-Cultural Study of Self-Determination. Personality and Social Psychology Bulletin, 27(8), 930-942. https://doi.org/10.1177/0146167201278002

Dekker, S., \& Fischer, R. (2008). Cultural Differences in Academic Motivation Goals: A Meta-Analysis Across 13 Societies. The Journal of Educational Research, 102(2), 99-110. https://doi.org/10.3200/JOER.102.2.99-110

Dubois-Comtois, K., Cyr, C., \& Moss, E. (2011). Attachment behavior and mother-child conversations as predictors of attachment representations in middle childhood: A longitudinal study. Attachment \& human development, 13(4), 335-357. https://doi.org/10.1080/14616734.2011.584455

Dunning, D. (2004). On the motives underlying social cognition. In M. B. Brewer, \& M. Heustone (Eds.), Emotion and motivation (pp. 137-164). Oxford, U.K: Blackwell Publishing Ltd.

Egeland, B., \& Farber, E. (1984). Infant-mother attachment: Factors related to its development and changes over time. Child development, 753-771. https://doi.org/10.2307/1130127

Fairbanks, L. (2003). Parenting. In D. Maestripieri (Ed.), Primate psychology (pp. 144-170). Cambridge, MA, US: Harvard University Press.

Goldstein, L. (1999). The relational zone: The role of caring relationships in the co-construction of mind. American Educational Research Journal, 36(3), 647-673. https://doi.org/10.3102/00028312036003647

Gottilieb, A. (2004). The afterlife is where we come from: Infants and infant care in West Africa.

Greenfield, P., \& Keller, H. (2004). Cultural psychology. Encyclopedia of applied psychology, 1, 545-554. https://doi.org/10.1016/B0-12-657410-3/00195-1

Harter, S. (1975). Developmental Differences in the Manifestation of Mastery Motivation on Problem-Solving Tasks. Child development, 46(2), 370-378. https://doi.org/10.2307/1128130

Hayamizu, T. (1997). Between Intrinsic and Extrinsic Motivation: Examination of Reasons for Academic Study based on the Theory of Internalization. Japanese Psychological Research, 39(2), 98-108. https://doi.org/10.1111/1468-5884.00043

Heckhausen, J. (1993). The development of mastery and its perception within caretaker-child dyads. Mastery Motivation: Children's investigation, persistence, and development, 55-79.

Heckhausen, J. (2004). The development of mastery and its perception within caretaker-child dyads. In D. J. Messer (Ed.), Mastery Motivation in early childhood: Development, measurement, and social processes (pp. 55-79). Retrieved from http://www.aleqt.com/2012/02/10/article_625071.html 
Iyengar, S., \& Lepper, M. (1999). Rethinking the value of choice: A cultural perspective on intrinsic motivation. Journal of Personality and Social Psychology, 76(3), 349-366. https://doi.org/10.1037/0022-3514.76.3.349

Jennings, K. (1993). Mastery Motivation and the formation of self-concept from infancy through early childhood. In D. J. Messer (Ed.), Mastery Motivation in early childhood: Development, measurement, and social processes (pp. 33-54). London: Routledge.

Keller, H. (2014). Introduction. In H. Otto, \& H. Keller (Eds.), Different faces of attachment: Cultural variations on a universal human need (pp. 4-6). Cambridge University Press. https://doi.org/10.1017/CBO9781139226684.002

Keller, H., Otto, H., Chen, X., \& Rubin, K. (2011). Different faces of autonomy. Socioemotional development in cultural context, 164-185.

Kelly, S., Brownell, C., \& Campbell, S. (2000). Mastery Motivation and Self-Evaluative Affect in Children: Longitudinal Relations with Maternal Behavior. Child development, 71(4), 1061-1071. https://doi.org/10.1111/1467-8624.00209

Khudairi, S. (2004). Social Problems of Houseworkers (Field Study). Faculaty of Literature Researches CenterKing Suad University, K.S.A.

Kwan, V., Bond, M., \& Singelis, T. (1997). Pancultural explanations for life satisfaction: Adding relationship harmony to self-esteem. Journal of Personality and Social Psychology, 73(5), 1038-1051. https://doi.org/10.1037/0022-3514.73.5.1038

Lamb, M., \& Malkin, C. (1986). The development of social expectations in distress-relief sequences: A longitudinal study. International Journal of Behavioral Development, 9(2), 235-249. https://doi.org/10.1177/016502548600900207

Lancy, D. F. (2014): “Babies aren’t persons”: A servey of delayed personhood. In H. Otto, \& H. Keller (Eds.), Different faces of attachment. Cultural variations on a universal human need. Cambridge University Press. https://doi.org/10.1017/CBO9781139226684.006

Landry, S., Smith, K., Swank, P., \& Miller-Loncar, C. (2000). Early maternal and child influences on children's later independent cognitive and social functioning. Child development, 71(2), 358-375. https://doi.org/10.1111/1467-8624.00150

Levine, R. (2014). Attachment theory as cultural ideology. In H. Otto, \& H. Keller (Eds.), Different faces of attachment: Cultural variations on a universal human need (p. 50). Cambridge University Press. https://doi.org/10.1017/CBO9781139226684.005

Lieberman, M., Doyle, A., \& Markiewicz, D. (1999). Developmental patterns in security of attachment to mother and father in late childhood and early adolescence: Associations with peer relations. Child development, 70(1), 202-213. https://doi.org/10.1111/1467-8624.00015

Lounds, J., Borkowski, J., Whitman, T., Maxwell, S., \& Weed, K. (2005). Adolescent Parenting and Attachment During Infancy and Early Childhood. Parenting: Science and Practice, 5(1), 91-118. https://doi.org/10.1207/s15327922par0501_4

Markus, H., \& Kitayama, S. (1991). Culture and the self: Implications for cognition, emotion, and motivation. Psychological review, 98(2), 224. https://doi.org/10.1037/0033-295X.98.2.224

Meehan, C., \& Hawks, S. (2014). Maternal and allomaternal responsiveness: The significance of cooperative caregiving in attachment theory. In H. Otto \& H. Keller (Eds.), Different faces of attachment (pp. 113-140). U.K: Cambridge University Press. https://doi.org/10.1017/CBO9781139226684.008

Moneta, G. (2004). The Flow Model of Intrinsic Motivation in Chinese: Cultural and Personal Moderators. Journal of Happiness Studies, 5(2), 181-217. https://doi.org/10.1023/B:JOHS.0000035916.27782.e4

Monrat, D. (2004). Mastery Motivation in early childhood: Development, measurement, and social processes. Psychology Press.

Morgan, G. A., Busch-Rossnagel, N. A., Barrett, K. C., \& Wang, J. (2009). The Dimensions of Mastery Questionnaire (DMQ): A Manual About Its Development, Psychometrics, and Use. Colorado State University. http://mathijsvervloed.nl/onewebmedia/DMQmanual(05-11-2009).pdf

O'Connor, E., Collins, B., \& Supplee, L. (2012). Behavior problems in late childhood: The roles of early maternal attachment and teacher-child relationship trajectories. Attachment \& human development, 14(3), 
265-288. https://doi.org/10.1080/14616734.2012.672280

Oishi, S., Diener, E., Lucas, R., \& Suh, E. (1999). Cross-Cultural Variations in Predictors of Life Satisfaction: Perspectives from Needs and Values. Personality and Social Psychology Bulletin, 25(8), 980-990. https://doi.org/10.1177/01461672992511006

Otto, H., \& Keller, H. (2014). Different faces of attachment: Cultural variations on a universal human need. Cambridge University Press. https://doi.org/10.1017/CBO9781139226684

Pearce, C. (2009). A short introduction to attachment and attachment disorder. London and Philadelphia: Jessica Kingsley Publishers.

Pederson, D., Moran, G., Sitko, C., Campbell, K., Ghesquire, K., \& Acton, H. (1990). Maternal sensitivity and the security of infant-mother attachment: AQ-sort study. Child development, 61(6), 1974-1983. https://doi.org/10.2307/1130851

Pierrehumbert, B., Miljkovitch, R., Plancherel, B., Halfon, O., \& Ansermet, F. (2000). Attachment and temperament in early childhood: Implications for later behavior problems. Infant and Child Development, 9(1), 17-32. https://doi.org/10.1002/(SICI)1522-7219(200003)9:1<17::AID-ICD212>3.0.CO;2-\#

Posada, G., Gao, Y., Wu, F., Posada; R., Tascon, M., \& Synnevaag, B. (1995). The Secure-Base Phenomenon across Cultures: Children's Behavior, Mothers' Preferences, and Experts' Concepts. Monographs of the Society for Research in Child Development, 60(2/3), 27-48. https://doi.org/10.2307/1166169

Raikes, H., \& Thompson, R. (2008). Attachment security and parenting quality predict children's problem-solving, attributions, and loneliness with peers. Attachment \& human development, 10(3), 319-344. https://doi.org/10.1080/14616730802113620

Ryan, R., Chirkov, V., Little, T., Sheldon, K., Timoshina, E., \& Deci, E. (1999). The American Dream in Russia: Extrinsic Aspirations and Well-Being in Two Cultures. Personality and Social Psychology Bulletin, 25(12), 1509-1524. https://doi.org/10.1177/01461672992510007

Schwartz, S. (1994). Beyond individualism/collectivism: New cultural dimensions of values. In U. Kim, H. C. Triandis, Ç. Kâğitçibaşi, S. C. Choi, \& G. Yoon (Eds.), Individualism and collectivism: Theory, method, and applications (pp. 85-119). Thousand Oaks, CA, US: Sage Publications, Inc.

Sheldon, K., Elliot, A., Kim, Y., \& Kasser, T. (2001). What is satisfying about satisfying events? Testing 10 candidate psychological needs. Journal of Personality and Social Psychology, 80(2), 325-339. https://doi.org/10.1037/0022-3514.80.2.325

Sivan, E. (1986). Motivation in Social Constructivist Theory. Educational Psychologist, 21(3), 209-233. https://doi.org/10.1207/s15326985ep2103_4

Thompson, R., Laible, D., \& Ontai, L. (2003). Early understandings of emotion, morality, and self: Developing a working model. Advances in child development and behavior, 31, 139-172.

Vaughn, B. \& Waters, E. (1990). Attachment behavior at home and in the laboratory: Q-sort observations and strange situation classifications of one-year-olds. Child development, 61(6), 1965-1973. https://doi.org/10.2307/1130850

Vygotsky, L. (1993). Introduction: The Fundamental Problems of Defectology. In R. W. Rieber, \& A. S. Carton (Eds.), The Collected Works of L.S. Vygotsky: The Fundamentals of Defectology (Abnormal Psychology and Learning Disabilities) (pp. 29-51). New York: Plenum Press.

Walker, R., Pressick-Kilborn, K., Sainsbury, E., \& MacCallum, J. (2010). A sociocultural approach to motivation: A long time coming but here at last. In T. C. Urdan, \& S. A. Karabenick (Eds.), The Decade Ahead: Applications and Contexts of Motivation and Achievement (Vol. 16B, pp. 1-42): Emerald Group Publishing Limited. https://doi.org/10.1108/s0749-7423(2010)000016b004

Wang, J., Morgan, G., \& Biringen, Z. (2014). Mother-Child Affect Exchanges and Children's Mastery Behaviours during Preschool Years. Infant and Child Development, 23(2), 139-152. https://doi.org/10.1002/icd.1825

Wang, P., Hwang, A., Liao, H., Chen, P., \& Hsieh, W. (2011). The stability of Mastery Motivation and its relationship with home environment in infants and children. Infant Behavior and Development, 34(3), 434-442. https://doi.org/10.1016/j.infbeh.2011.04.005

Wang, P., Morgan, G., Hwang, A., \& Liao, H. (2013). Individualized Behavioral Assessments and Maternal 
Ratings of Mastery Motivation in Mental Age-Matched Children With and Without Motor Delay. Physical therapy, 93(1), 79-87. https://doi.org/10.2522/ptj.20120068

Watson, J. (1966). The development and generalization of "contingency awareness" in early infancy: Some hypotheses. Merrill-Palmer Quarterly of Behavior and Development, 12(2), 123-135.

Wood, D., \& Graham, S. (2010). Why race matters: social context and achievement motivation in African American youth. The Decade Ahead: Applications and Contexts of Motivation and Achievement: Applications and Contexts of Motivation and Achievement, 16, 175. https://doi.org/10.1108/S0749-7423(2010)000016B009

Young, J., \& Hauser-Cram, P. (2006). Mother-child interaction as a predictor of Mastery Motivation in children with disabilities born preterm. Journal of Early Intervention, 28(4), 252-263. https://doi.org/10.1177/105381510602800402

\section{Copyrights}

Copyright for this article is retained by the author(s), with first publication rights granted to the journal.

This is an open-access article distributed under the terms and conditions of the Creative Commons Attribution license (http://creativecommons.org/licenses/by/4.0/). 